\title{
Tenosynovial giant cell tumor of the cervical spine: a case report
}

\author{
Ryogo Furuhata ${ }^{1} \cdot$ Akio Iwanami $^{2} \cdot$ Osahiko Tsuji ${ }^{1} \cdot$ Narihito Nagoshi $^{1} \cdot$ Satoshi Suzuki $^{1} \cdot$ Eijiro Okada $^{1}$. \\ Nobuyuki Fujita ${ }^{1} \cdot$ Mitsuru Yagi $^{1} \cdot$ Morio Matsumoto $^{1} \cdot$ Masaya Nakamura $^{1} \cdot$ Kota Watanabe $^{1}$
}

Received: 10 January 2019 / Revised: 6 February 2019 / Accepted: 15 February 2019

(C) International Spinal Cord Society 2019

\begin{abstract}
Introduction Tenosynovial giant cell tumors (TSGCTs) generally occur in the limb joints, and only rarely in the spine. This case report describes a patient with TSGCT of the spine at $\mathrm{C} 1-\mathrm{C} 2$, which was treated surgically and diagnosed as TSGCT. Case presentation A 32-year-old woman with a 4-month history of neck pain and numbness in both upper extremities was referred to our department. Magnetic resonance imaging (MRI) revealed a neoplastic lesion extending from the left epidural space to the erector spinae muscles at the $\mathrm{C} 1-\mathrm{C} 2$ vertebral level, which was isointense on T1-weighted images, heterogeneously hypointense on T2-weighted images, and showed heterogeneous enhancement on gadopentetate dimeglumine (Gd-DTPA)-enhanced T1-weighted images. Computed tomography showed no findings suggestive of bone destruction of the vertebral body. Because the neurological symptoms were progressive, total macroscopic resection of the tumor was performed via a posterior approach. Histopathological examination of the resected specimen revealed the diagnosis of TSGCT. Improvement of the both the neck pain and upper-extremity numbness was noted postoperatively. An MRI obtained 6 months after the surgery revealed no evidence of tumor recurrence and the postoperative course was uneventful. Discussion TSGCT of the upper cervical spine $(\mathrm{C} 1-\mathrm{C} 2)$ is rare, and this is the tenth reported case. If a tumor is heterogeneously hypointense on T2-weighted MRI, which reflects hemosiderosis, the possibility of this tumor should be considered in the differential diagnosis.
\end{abstract}

\section{Introduction}

Tenosynovial giant cell tumor (TSGCT) is a fibrohistiocytic tumor arising from the tendon sheath, synovium, or bursa and is pathologically characterized by proliferation of mononuclear synovial-like cells and the presence of osteoclast-like multinucleated giant cells and hemosiderinladen macrophages [1]. TSGCT usually occurs in the limb joints and rarely in the spine. This case report describes a patient with TSGCT of the spine at $\mathrm{C} 1-\mathrm{C} 2$.

Akio Iwanami

akioiwanami@gmail.com

1 Department of Orthopaedic Surgery, School of Medicine, Keio University, Tokyo, Japan

2 Department of Orthopaedic Surgery, Spine Center, Koga Hospital, Ibaraki, Japan

\section{Case presentation}

A 32-year-old woman with a 4-month history of neck pain and numbness in the upper extremities were referred to our department. She had no history of trauma. On physical examination, she had impaired dexterity and weakness of the left wrist extensor muscles.

Magnetic resonance imaging (MRI) revealed a neoplastic lesion extending from the left epidural space to the paravertebral muscles at $\mathrm{C} 1-\mathrm{C} 2$, which was isointense on $\mathrm{T} 1-$ weighted images (T1WI) and heterogeneously hypointense on T2-weighted images (T2WI) and showed heterogeneous enhancement on gadopentetate dimeglumine (Gd-DTPA)enhanced T1WI (Fig. 1a-e). The cervical spinal cord was displaced to the left laterally by the tumor and T2WI showed changes in intramedullary signal intensity (Fig. 1f). No bone erosion was seen on computed tomography (CT) (Fig. 2).

From these findings, the tumor was diagnosed as a cervical spine tumor at $\mathrm{C} 1-\mathrm{C} 2$. Neurinoma, meningioma, neurofibroma, and other tumors were considered in the differential diagnosis. 
Fig. 1 Magnetic resonance images of the cervical spine showing a mass extending from the left epidural space to the paravertebral muscles at the $\mathrm{C} 1 /$ C2 level. a Axial T1-weighted image showing a lesion with heterogeneous isointensity. b Axial T2-weighted image showing a lesion with heterogeneous low signal intensity. c Axial T1-weighted image after administration of intravenous gadolinium-DTPA (dimeglumine) showing obvious gadolinium-DPTA

enhancement. d Sagittal T2weighted image showing an isointense mass at $\mathrm{C} 1 / \mathrm{C} 2$. e, f Sagittal T2-weighted image showing a mass with low signal intensity and an intramedullary high signal intensity area at $\mathrm{C} 1 / \mathrm{C} 2$
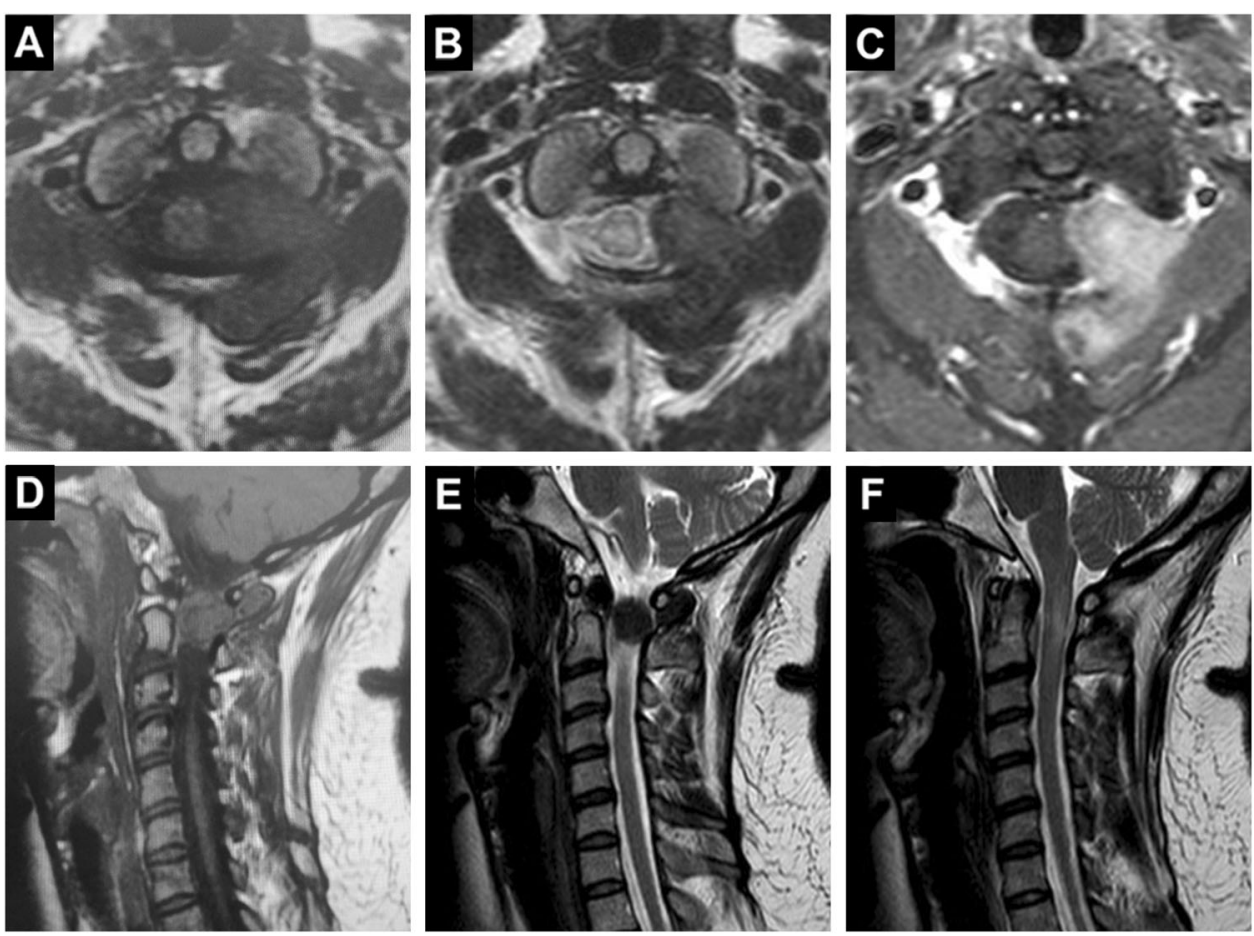
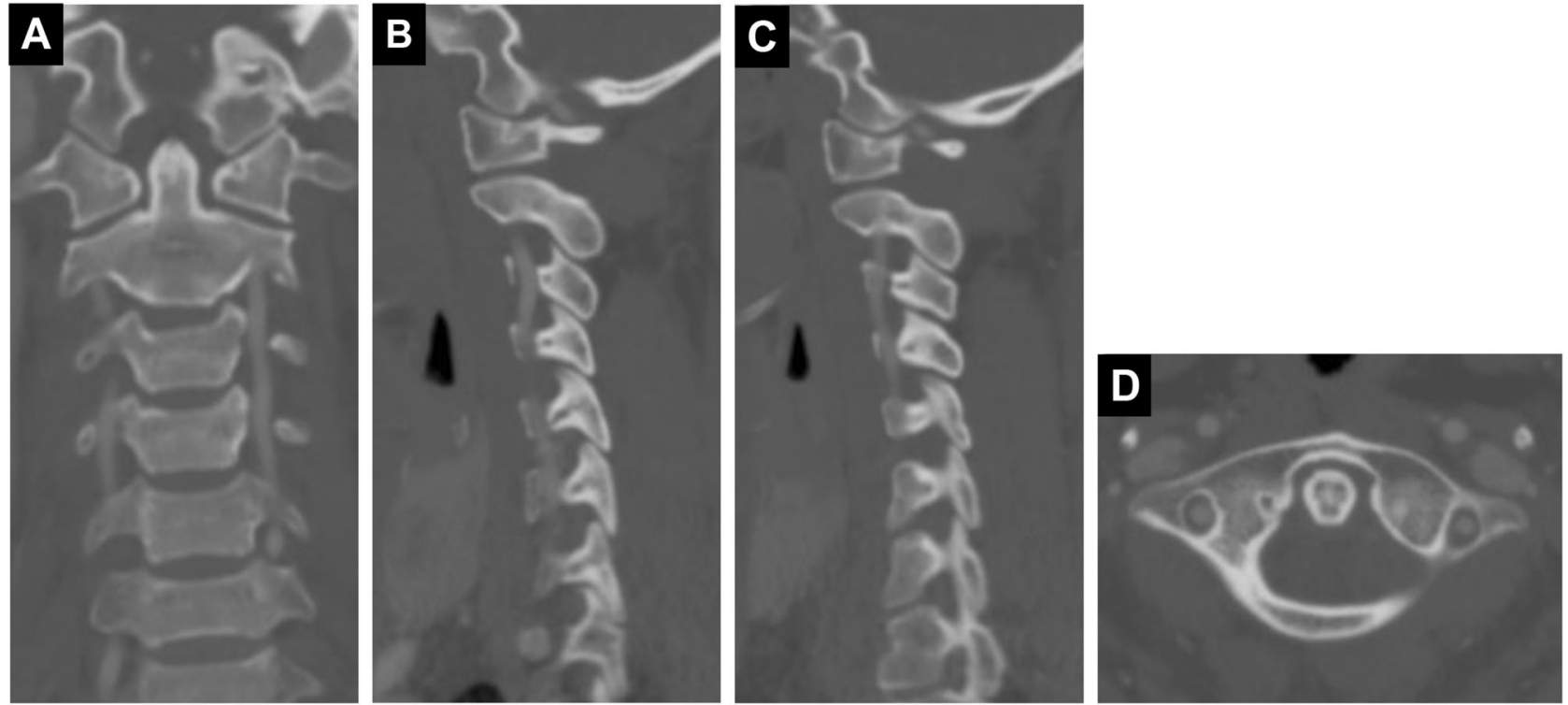

Fig. 2 Coronal (a), sagittal (b, c), and axial (d) computed tomographic images of the bone window showing no bone erosion

Her neurologic symptoms worsened, and tumor resection was scheduled. We performed laminectomy of the posterior arch at $\mathrm{C} 1$ and hemilaminectomy of the left vertebral arch at $\mathrm{C} 2$, and achieved total macroscopic tumor resection.

Histopathologically, the resected specimen consisted of both tumor and normal tendon components (Fig. 3a). In the tumor component, hematoxylin and eosin staining showed proliferation of mononuclear cells and some osteoclast-like multinucleated giant cells (Fig. 3b). Immunohistochemical staining for cluster of differentiation-68 and Factor XIIIa was positive. From these findings, the tumor was diagnosed as TSGCT.

After surgery, her symptoms improved. MRI at 3 years after the surgery revealed no recurrence (Fig. 4). 


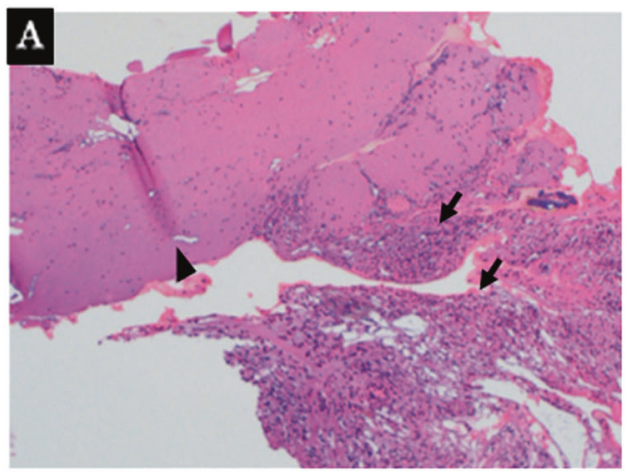

Fig. 3 Pathologic results. a Photomicrograph of the surgical specimen showing a cellular component composed of small mononuclear cells (arrows) and a normal tendon component (arrowheads) $(\times 40)$.

Fig. 4 Magnetic resonance images of the cervical spine at 3 years after the surgery. Axial (a) and sagittal (b) T1-weighted images after administration of intravenous gadolinium-DTPA (dimeglumine), and sagittal T2weighted image (c) showing no recurrence of tumor
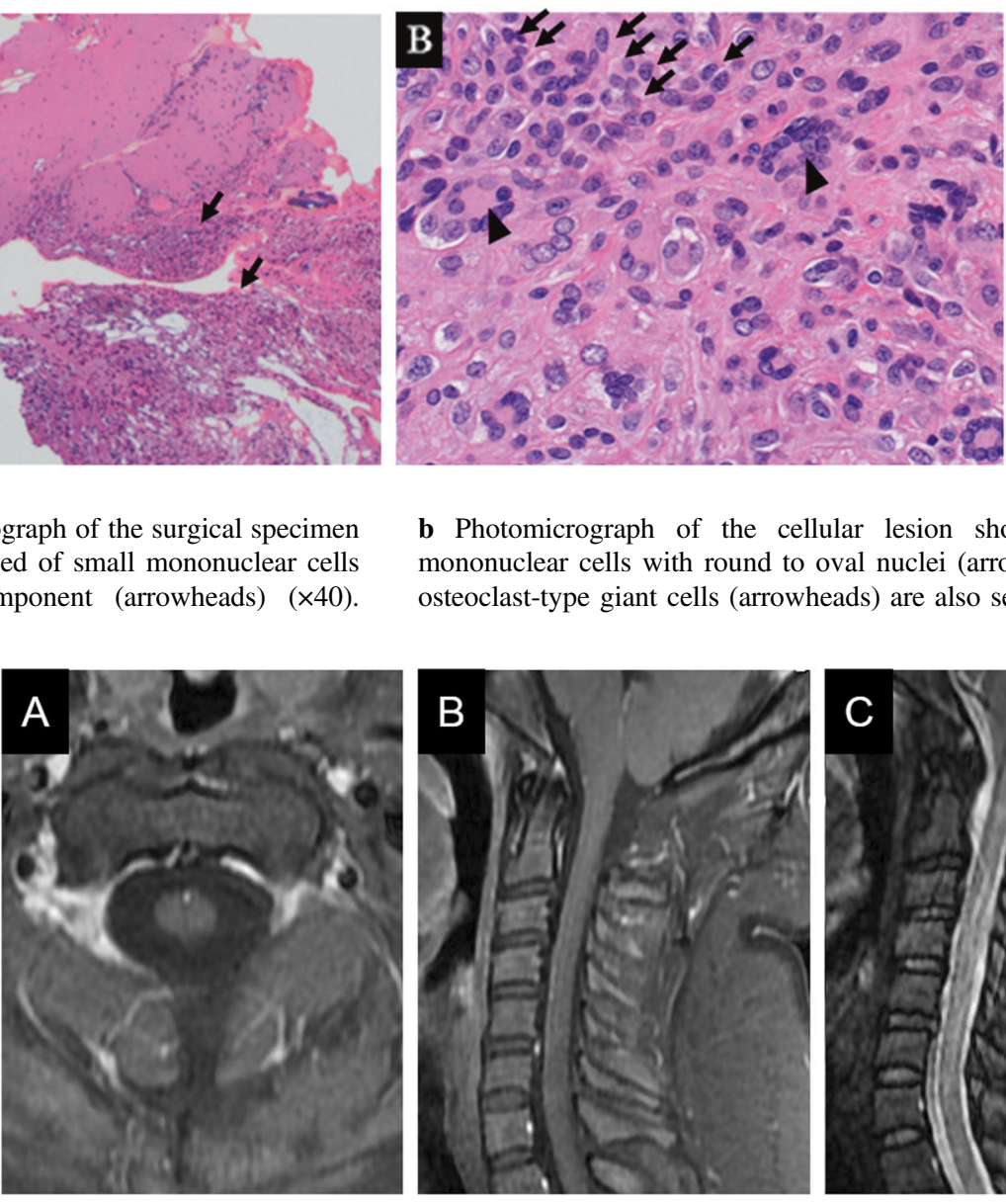

b Photomicrograph of the cellular lesion showing proliferative mononuclear cells with round to oval nuclei (arrow). Multinucleated osteoclast-type giant cells (arrowheads) are also seen $(\times 200)$
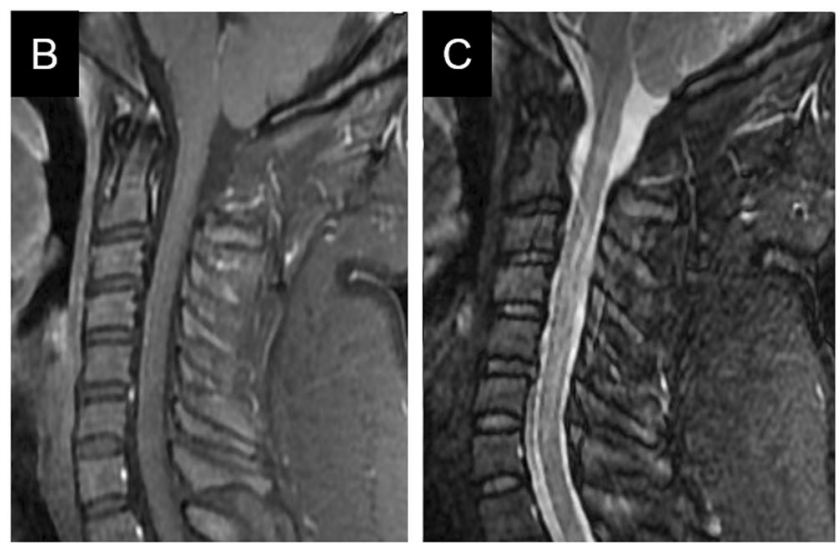

TSGCT. However, it is difficult to diagnose TSGCT preoperatively because of its rarity in the spine. CT shows bone erosion in at least 70\% of cases of TSGCT of the spine [12]. The mechanism of bone erosion is unknown, but the following hypotheses have been proposed: in one, an increase in intra-articular pressure caused by the tumor compressing the articular cartilage and bony cortex; [19] in another, the synovium deeply invades the bone tissue through the vasculature, leading to bone atrophy [20]. In many of the reported cases occurring in $\mathrm{C} 1-\mathrm{C} 2$, bone erosion was seen in the facet between $\mathrm{C} 1$ and $\mathrm{C} 2$ or atlantoaxial joint, suggesting that the tumors originated from these sites. However, it has also been reported that there were no obvious bony lesions $[7,8,10]$, the origins of the tumors were speculated to be the bursa [7] or vertebra membrane [10] in such cases. In our case, CT showed no bony lesion in the facet or atlantoaxial joint, suggesting that the tumor may have originated from the bursa or vertebra membrane, as in the previously reported cases [7, 10], or from the tendon sheath of the paravertebral muscles.

Gross total resection is recommended for the treatment of TSGCT. The recurrence rate of TSGCT in the spine is $18-25 \%[3,21]$, which is equivalent to that in the limbs 


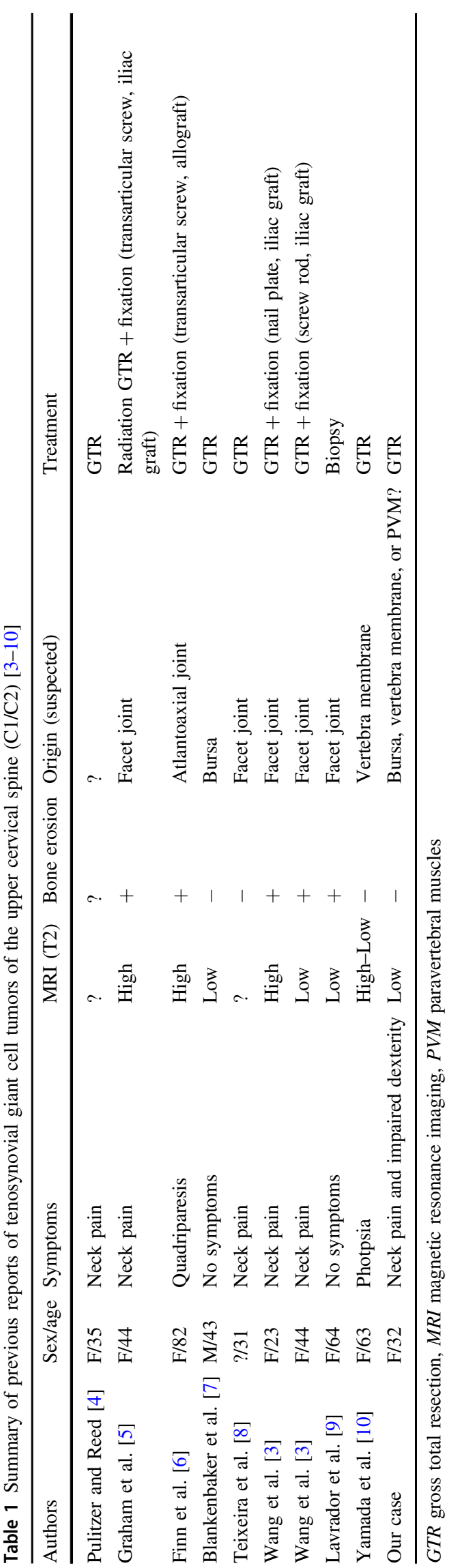

$[22,23]$. The recurrence rates after gross total resection and subtotal resection were $6.7 \%$ and $66.7 \%$, respectively, and incomplete resection often resulted in recurrence [3]. For a recurrent case, molecularly targeted therapy using imatinib, nilotinib, emactuzumab, and PLX3397, which targets the colony-stimulating factor 1 receptor (overexpressed in TSGCT), may be a useful treatment option [24-29]. In cases of TSGCT affecting $\mathrm{C} 1-\mathrm{C} 2$ with marked bone destruction or intervertebral instability, fixation should be considered in addition to tumor resection (Table 1) $[3,5,6]$. However, we believe that tumor resection alone was adequate in this case because preoperative imaging showed no bone destruction or instability.

TSGCT of the upper cervical spine $(\mathrm{C} 1-\mathrm{C} 2)$ is rare. If a tumor is heterogeneously hypointense on T2WI, TSGCT should be considered in the differential diagnosis. We performed tumor resection alone in this case because preoperative imaging showed no bone destruction or instability at $\mathrm{C} 1-\mathrm{C} 2$.

\section{Compliance with ethical standards}

Conflict of interest The authors declare that they have no conflict of interest.

Publisher's note: Springer Nature remains neutral with regard to jurisdictional claims in published maps and institutional affiliations.

\section{References}

1. Fletcher CDM, Bridge JA, Hogendoorn P, Mertens F. WHO classification of tumours of soft tissue and bone. 4th edn. Lyon: IARC Press; 2013.

2. Kleinman GM, Dagi TF, Poletti CE. Villonodular synovitis in the spinal canal: case report. J Neurosurg. 1980;52:846-8.

3. Wang K, Zhu B, Yang S, Liu Z, Yu M, Liu X. Primary diffusetype tenosynovial giant cell tumor of the spine: a report of 3 cases and systemic review of the literature. Turk Neurosurg. 2014;24:804-13.

4. Pulitzer DR, Reed RJ. Localized pigmented villonodular synovitis of the vertebral column. Arch Pathol Lab Med. 1984;108:228-30.

5. Graham E, Kuklo TR, Kyriakos M, Rubin DA, Riew KD. Invasive pigmented villonodular synovitis of the atlantoaxial joint: a case report. J Bone Jt Surg Am. 2002;84:1856-60.

6. Finn MA, McCall TD, Schmidt MH. Pigmented villonodular synovitis associated with pathological fracture of the odontoid and atlantoaxial instability. Case Report Rev Lit J Neurosurg Spine. 2007;7:248-53.

7. Blankenbaker DG, Tuite MJ, Koplin SA, Salamat MS, Hafez R. Tenosynovial giant cell tumor of the posterior arch of C1. Skelet Radiol. 2008;37:667-71.

8. Teixeira WG, Lara NA Jr, Narazaki DK, de Oliveira C, Cavalcanti C, Marins LV, et al. Giant-cell tumor of the tendon sheath in the upper cervical spine. J Clin Oncol. 2012;30:e250-3.

9. Lavrador JP, Oliveira E, Gil N, Francisco AF, Livraghi S. C1-C2 pigmented villonodular synovitis and clear cell carcinoma: unexpected presentation of a rare disease and a review of the literature. Eur Spine J. 2015;24:S465-71. 
10. Yamada S, Oshima K, Hamada K, Sotobori T, Joyama S, Hashimoto N, et al. Giant cell tumor of the tendon sheath arising from a membrane suttounding the posterior arch of $\mathrm{C} 1$ : a case report. Spine J. 2016;16:e353-7.

11. Motamedi K, Murphey MD, Fetsch JF, Furlong MA, Vinh TN, Laskin WB, et al. Villonodular synovitis (PVNS) of the spine. Skelet Radiol. 2005;34:185-95.

12. Furlong MA, Motamedi K, Laskin WB, Vinh TN, Murphey M, Sweet DE, et al. Synovial-type giant cell tumors of the vertebral column: a clinicopathologic study of 15 cases, with a review of the literature and discussion of the differential diagnosis. Hum Pathol. 2003;34:670-9.

13. Doita M, Miyamoto H, Nishida K, Nabeshima Y, Yoshiya S, Kurosaka M. Giant-cell tumor of the tendon sheath involving the thoracic spine. J Spinal Disord Tech. 2005;18:445-8.

14. Parmar HA, Sitoh YY, Tan KK, Teo J, Ibet SM, Hui F. MR imaging features of pigmented villonodular synovitis of the cervical spine. Am J Neuroradiol. 2004;25:146-9.

15. Jelinek JS, Kransdorf MJ, Utz JA, Berrey BH Jr, Thomson JD, Heekin $\mathrm{RD}$, et al. Imaging of pigmented villonodular synovitis with emphasis on MR imaging. Am J Roentgenol. 1989;152:337-42.

16. Hughes TH, Sartoris DJ, Schweitzer ME, Resnick DL. Pigmented villonodular synovitis: MRI characteristics. Skelet Radiol. 1995;24:7-12.

17. Lin J, Jacobson JA, Jamadar DA, Ellis JH. Pigmented villonodular synovitis and related lesions: the spectrum of imaging findings. Am J Roentgenol. 1999;172:191-7.

18. Llauger J, Palmer J, Rosón N, Cremades R, Bagué S. Pigmented villonodular synovitis and giant cell tumors of the tendon sheath: radiologic and pathologic features. Am J Roentgenol. 1999;172:1087-91.

19. Chung SM, Janes JM. Diffuse pigmented villonodular synovitis of the hip joint. Review of the literature and report of four cases. $\mathrm{J}$ Bone Jt Surg Am. 1965;47:293-303.
20. Scott PM. Bone lesions in pigmented villonodular synovitis. J Bone Jt Surg Br. 1968;50:306-11.

21. Giannini C, Scheithauer BW, Wenger DE, Unni KK. Pigmented villonodular synovitis of the spine: a clinical, radiological, and morphological study of 12 cases. J Neurosurg. 1996;84:592-7.

22. Schwartz HS, Unni KK, Pritchard DJ. Pigmented villonodular synovitis. A retrospective review of affected large joints. Clin Orthop Relat Res. 1989;247:243-55.

23. Oh SW, Lee MH, Eoh W. Pigmented villonodular synovitis on lumbar spine: a case report and literature review. J Korean Neurosurg Soc. 2014;56:272-7.

24. Blay JY, El Sayadi H, Thiesse P, Garret J. Ray-Coquard. Complete response to imatinib in relapsing pigmented villonodular synovitis/tenosynovial giant cell tumor (PVNS/TGCT). Ann Oncol. 2008;19:821-2.

25. Cassier PA, Gelderblom H, Stacchiotti S, Thomas D, Maki RG, Kroep JR, et al. Efficacy of imatinib mesylate for the treatment of locally advanced and/or metastatic tenosynovial giant cell tumor/ pigmented villonodular synovitis. Cancer. 2012;118:1649-55.

26. Brownlow N, Russell AE, Saravanapavan H, Wiesmann M, Murray JM, Manley PW, et al. Comparison of nilotinib and imatinib inhibition of FMS receptor signaling, macrophage production and osteoclastogenesis. Leukemia. 2008;22:649-52.

27. Cassier PA, Italiano A, Gomez-Roca CA, Le Tourneau C, Toulmonde M, Cannarile MA, et al. CSF1R inhibition with emactuzumab in locally advanced diffuse-type tenosynovial giant cell tumours of the soft tissue: a dose-escalation and dose-expansion phase 1 study. Lancet Oncol. 2015;16:949-56.

28. Tap WD, Wainberg ZA, Anthony SP, Ibrahim PN, Zhang C, Healey JH, et al. Structure-guided blockade of CSF1R kinase in tenosynovial giant-cell tumor. N Engl J Med. 2015;373:428-37.

29. Brahmi M, Vinceneux A, Cassier PA. Current systemic treatment options for tenosynovial giant cell tumor/pigmented villonodular synovitis: targeting the CSF1/CSF1R axis. Curr Treat Options Oncol. 2016;17:10. 